\title{
Reflexões sobre os desinvestimentos da Petrobras no segmento de refino
}

\section{Reflections on the Sale of Petrobras' Assets in the Refining Segment}

\author{
CÁSSIO GARCIA RIBEIRO GARCIA RIBEIRO (D) \\ MARCELO SARTORIO LOURAL ID
}

VALÉRIA SILVA MORTARID

\section{RESUMO}

Este artigo pretende explorar a estratégia de desinvestimentos colocada em marcha pela direção da Petrobras no setor de refino, a partir da década de 2020. A metodologia empregada se apoia em revisão bibliográfica, análise de dados secundários e pesquisa documental. Este estudo evidencia que a integração vertical representa o modelo hegemônico entre as grandes companhias de petróleo. Nesse modelo, a atividade de refino permite a diluição dos riscos associados às oscilações cambiais e no preço do barril de petróleo, contrabalançando eventuais perdas na área de Exploração e Produção quando o preço do óleo bruto está em baixa. O refino também desempenha um papel importante do ponto de vista da geração de fluxo de caixa futuro, especialmente em contextos de câmbio desvalorizado. Nesse sentido, há que se questionar se a estratégia de alienação de ativos é de fato a mais apropriada à Petrobras.

Palavras-chave: Petrobras, refino, integração vertical.

\section{Abstract}

This article intends to explore the divestment strategy set in motion by Petrobras management in the refining sector, starting in the 2020s. The methodology employed is based on a bibliographic review, analysis of secondary data and documentary research. 
This study shows that vertical integration represents the hegemonic model among the major oil companies. In this model, the refining activity allows the dilution of the risks associated with exchange rate fluctuations and the price of a barrel of oil, offsetting any losses in the Exploration and Production area when crude oil prices are low. Refining also plays an essential role in generating future cash flow, especially in devalued exchange contexts. In this sense, it is necessary to question whether the asset disposal strategy is the most appropriate for Petrobras.

Key-words: Petrobras, refining sector, vertical integration

\section{INTRODUÇÃo}

Uma firma que participa em mais do que um estágio sucessivo de produção ou distribuição de bens e serviços pode ser considerada verticalmente integrada (Carlton e Perloff, 2005). Tal estratégia corporativa é marcante entre as grandes companhias de petróleo, estatais e privadas. A indústria petrolífera tem como alvo a conversão do estoque de reservas de hidrocarbonetos em um fluxo regular de abastecimento de derivados, tais como gasolina e diesel. Assim, as grandes companhias de petróleo realizam: i) atividades a montante da cadeia, quais sejam, Exploração e Produção (E\&P) de petróleo e gás natural e; ii) atividades a jusante da cadeia, ligadas ao transporte, refino e distribuição de derivados de petróleo e gás natural (Furtado e Muller, 1995).

A integração vertical é a estratégia corporativa adotada pela Petrobras. Todavia, percebe-se uma guinada na gestão da empresa desde o mandato de Pedro Parente ${ }^{1}$. Uma das principais características dessa guinada é justamente a venda de ativos a jusante da cadeia petrolífera. A partir do "Relatório de sustentabilidade 2019" (Petrobras, 2019), depreende-se que durante a gestão de Roberto Castello Branco ${ }^{2}$, cristalizou-se a intenção de se reduzir a fatia de participação da estatal no mercado brasileiro de refino, situada atualmente em $98 \%$, para menos de $50 \%$, a partir da venda de algumas plantas de refino.

A finalidade deste estudo é avaliar se a estratégia que está sendo posta em prática pela atual gestão da Petrobras no setor de

Presidente da Petrobras entre maio de 2016 e junho de 2018.

2 Presidente da Petrobras entre janeiro 2019 e março de 2021. 
refino é de fato a mais apropriada à empresa. Este estudo se justifica, por três razões principais: i) a Petrobras contribui com parcela expressiva da produção de óleo bruto e derivados de petróleo consumidos no país, mesmo após a quebra do monopólio ocorrida em 1997, conforme será destacado na terceira seção deste artigo; ii) os derivados do petróleo, como gasolina e diesel, representaram, em 2019 , cerca de $80 \%$ do consumo energético atrelado ao transporte de cargas, coletivo e individual no país (EPE, 2020); iii) a mudança de rota está em curso, de modo que carece de estudos que se proponham a analisar as consequências desse processo.

A metodologia empregada neste estudo se apoia em revisão bibliográfica, análise de dados secundários e pesquisa documental. No que diz respeito à revisão da literatura, tal procedimento envolveu a seleção e leitura de trabalhos acadêmicos que versam sobre: i) o perfil do setor petrolífero internacional, especialmente no que diz respeito ao modelo de negócios hegemônico na atualidade entre as grandes petrolíferas (privadas e estatais); ii) o perfil de atuação da Petrobras (pré e pós-quebra do monopólio) dentro do setor petrolífero brasileiro. Além disso, este artigo conta também com a análise de dados secundários fornecidos por bases nacionais (tais como a Pesquisa Industrial Anual - PIA/IBGE e os Anuários Estatísticos da Agência Nacional do Petróleo, Gás Natural e Biocombustíveis - ANP) e estrangeiras (como a BP Statistical Review, da British Petroleum). Quanto à pesquisa documental, de modo semelhante ao que foi elaborado por Fehlauer, Vieira e Claro (2019) ela envolveu a análise dos relatórios anuais divulgadas pelas grandes "players" do setor petrolífero, dentre as quais a própria Petrobras.

Com base nos resultados deste estudo, deve-se questionar a estratégia que está sendo colocada em prática pela atual direção da Petrobras de alienação de ativos no setor de refino, pois: i) tal estratégia coloca a empresa distante do modelo hegemônico adotado pelas grandes companhias de petróleo e, consequentemente, das vantagens obtidas pelas empresas que o adotam; ii) o segmento de refino pode ser lucrativo, além de trazer grande resiliência à empresa a oscilações cambiais e reduções no preço do petróleo; iii) dado "ii" e considerando que o parque de refino da Petrobras opera com capacidade ociosa na atualidade, com o aumento que tem se 
observado na produção de óleo bruto (em virtude da entrada em operação dos reservatórios do pré-sal) no país, tal empresa poderia aproveitar tal cenário para aumentar sua participação no mercado brasileiro de derivados e, quiçá, exportar o excedente.

Este artigo conta com mais três seções, além desta introdução. Na segunda seção é apresentada uma discussão acerca do papel que a lógica de integração vertical assume dentro do modelo de negócios das grandes companhias de petróleo (privadas e estatais), enfatizando qual o peso e a importância da atividade de refino do ponto de vista desse modelo. A terceira seção é dedicada à Petrobras e perpassa dois tópicos principais: i) a importância do refino no perfil verticalmente integrado da Petrobras; ii) a crise na Petrobras e a mudança de estratégia para o setor de refino. Na última seção são apresentadas as considerações finais deste estudo.

\section{ESTRATÉGIA DE INTEGRAÇÃo VERTICAL: O CASO DA INDÚSTRIA PETROLÍFERA}

As pesquisas em torno da estratégia de integração vertical de empresas têm sido levadas a cabo no campo das teorias da firma. Tais estudos buscam responder quais as motivações para uma firma se integrar-se verticalmente, quais atividades podem ou não ser integradas, quais resultados podem ser atingidos com base nessa estratégia e quais as implicações positivas e negativas da integração vertical sobre a concorrência. Antes de apresentarmos a literatura que aborda tal fenômeno e de entrarmos no caso da indústria petrolífera, é importante destacar que nem sempre as empresas alcançam vantagens com a integração, isto é, que dominar todas as etapas da cadeia produtiva é vantajoso às empresas. Trata-se de uma visão equivocada, uma vez que desconsidera as especificidades dos setores e herda a concepção "neoclássica, que alia integração a poder de mercado e, portanto a renda monopolísticas" (Zylbersztajn, 1995, p. 67)

Coase (1937) foi o precursor da Teoria dos Custos de Transação (TCT) e sua obra continua tendo grande importância na discussão acerca dos modelos alternativos de se coordenar as interações dos agentes, quais sejam: mercado versus firma (make or buy). $\mathrm{O}$ autor apregoava que os elevados custos de transação podiam ser traduzidos como uma debilidade do mercado, em situações na quais ele não 
se revela um meio eficiente de coordenação das atividades econômicas e de alocação dos recursos. Surgiriam quando compradores e vendedores tivessem interesses conflitantes. Assim, em casos como o descrito, faria sentido para a empresa internalizar atividades, com vistas a minimizar seus custos de transação.

Williamson $(1975 ; 1985)$ muitas décadas adiante revisitou o trabalho seminal de Coase acerca da TCT. Particularmente no que se refere à questão da integração vertical o autor chama a atenção para a presença ativa específicos, atrelada à existência dos chamados custos irrecuperável (sunk costs). De acordo com autor, tal fenômeno representa a principal fator para explicar a decisão das empresas de se integrarem verticalmente. Portanto, quanto maior a especificidades dos ativos, maior será o incentivo para a integração vertical. Williamson apregoa que em uma situação hipotética na qual se observa a existência de uma quantidade expressiva de ativos específicos, um ambiente transacional eivado de complexidade e incertezas, depreende-se que os custos para a negociação e implementação dos contratos são proibitivos. Nesse caso, o autor argumenta que como há um alto grau de especificidade dos ativos, a integração vertical é o modelo de gestão mais indicado.

Carlton e Perloff (2005) afirmam que em função da existência de alguns custos, as empresas integram-se verticalmente, apenas em situações nas quais os benefícios da integração superarem os custos dessa estratégia. De acordo com os autores as seis principais vantagens da integração são: i) redução dos custos do processo produtivo, notadamente dos custos de transação; ii) tal estratégia evita ou reduzir custos atrelados a restrições governamentais, tais como regulamentos e impostos; iii) aumento ou criação de poder de mercado (ou eliminação do poder de mercado de outras firmas); iv) eliminar falhas do mercado, como assimetria de informações.

Tebboune \& Urquhart (2016), partindo do arcabouço teórico da TCT, asseveram que o maior controle propiciado pela integração vertical, minimiza o problema da incerteza, considerando que investimentos em ativos específicos foram realizados. Zylbersztajn (2009) chama a atenção para a possibilidade de choques externos inesperados, cujos resultados podem ser imprevistos. Assim, de acordo com o autor, a incerteza representa uma motivação deveras 
importante para que as firmas aumentem o controle sobre a cadeia produtiva em que operam.

Com relação ao setor de petróleo, Barboza (1996) afirma que há vantagens importantes obtidas pelas petrolíferas que atuam em todos os elos produtivos, tais como: a ampliação do controle sobre a cadeia completa; a redução de riscos e a diminuição da vulnerabilidade frente a eventos como oscilações cambiais e no preço do barril de petróleo. Furtado e Muller (1995) argumentam que a competitividade das companhias petrolíferas está associada fundamentalmente à adoção do modelo de negócios em que seus investimentos não se restringem ao controle de reservas de hidrocarbonetos, como também dos mercados a jusante e das tecnologias de toda a cadeia petrolífera.

Valente (2009), explica que em primeiro lugar é importante que se considere que a indústria petrolífera é intensiva em capital. Partindo desse pressuposto, apenas as empresas integradas irão dispor de recursos para gerar um fluxo de renda abundante e estável, ou seja, terão fôlego financeiro para realizar investimentos para descobrir de novas jazidas. Segundo o autor, esses investimentos precisam acontecer continuamente, de maneira a preservar um horizonte de longo prazo nas atividades a montante da cadeia, permitindo que a empresa mantenha e incremente sua competitividade no setor petrolífero (Valente, 2009). Ruas (2012) assevera que o modelo hegemônico no setor petrolífero é aquele em que as companhias de petróleo atuam "do poço ao posto". Tal modelo torna possível maior estabilidade nos fluxos de receitas, além de aumentar a capacidade de planejamento das empresas, em relação a atividades envoltas em grande incerteza. De acordo com Ruas:

Pode-se afirmar que fontes de incerteza da indústria vão além dos tradicionais riscos à atividade produtiva, como custos, preços e demanda futura. O risco geológico - impossibilidade de mapeamento completo de reservas antes da perfuração de poços ou mesmo da efetivação do processo produtivo - e o risco político - ligado à estrutural instabilidade de regras e instituições que organizam as atividades em países produtores - ampliam a incerteza para a tomada de decisões na indústria petrolífera e atribui à verticalização de atividades uma grande vantagem no processo concorrência (Ruas, 2012, p. 14). 
Cabe observar que durante o século XX ocorreram diversas nacionalizações de reservas de petróleo e gás, que passaram a ser exploradas pelas chamadas Companhias Nacionais de Petróleo (no inglês, National Oil Companies - NOCs) recém-criadas. Diante desse novo cenário, as chamadas Companhias Internacionais de Petróleo (International Oil Companies - IOCs) buscaram novas localidades para realizar seus investimentos em E\&P e mantiveram o modelo de produção verticalmente integrado (POLITOVA, 2018).

Grandes companhias de petróleo enquadradas nesse grupo das IOCs, como são os casos da British Petroleum (BP), Total, Shell, Exxommobil e Chevron, se auto-declaram empresas verticalmente integradas em documentos como planos estratégicos e relatórios anuais. Extrai-se desses documentos a ideia de que a existência de um portfólio diversificado confere a essas empresas resiliência e flexibilidade no processo de tomada de decisões, em conformidade com as oscilações no mercado.

A adoção do modelo de integração produtiva por parte da BP fica evidente a partir do seguinte trecho extraído do relatório anual da empresa:

Nós temos um portfólio diversificado em diferentes atividades, tipos de recursos e regiões geográficas. Tendo participação nas atividades upstream e downstream, juntamente com capacidades de negociação bem estabelecidas, o que nos auxilia a mitigar o impacto de ciclo de preços baixos das commodities (BP, 2018, p. 6).

O perfil de cinco IOCs selecionadas (a BP, a Total, a Shell, a Exxommobil e a Chevron) no que se refere à produção de óleo cru, refino e vendas de derivados é ilustrada na Tabela 1. 
Tabela 1 - Produção de petróleo, refino e vendas de produtos derivados de petróleo por empresas selecionadas entre 2012 e 2017 (mil barril/dia)

\begin{tabular}{|c|c|c|c|c|}
\hline & Ano & $\begin{array}{l}\text { Produção de } \\
\text { óleo cru }\end{array}$ & Refino & Vendas \\
\hline \multirow{6}{*}{ Chevron } & 2012 & 1.764 & 1.702 & 2.765 \\
\hline & 2013 & 1.731 & 1.638 & 2.711 \\
\hline & 2014 & 1.700 & 1.600 & 2.710 \\
\hline & 2015 & 1.744 & 1.702 & 2.735 \\
\hline & 2016 & 1.719 & 1.688 & 2.675 \\
\hline & 2017 & 1.723 & 1.661 & 2.69 \\
\hline \multirow{6}{*}{ BP } & 2012 & 1.179 & 2.354 & 5.657 \\
\hline & 2013 & 1.083 & 1.791 & 5.569 \\
\hline & 2014 & 1.007 & 1.721 & 5.32 \\
\hline & 2015 & 1.099 & 1.705 & 5.605 \\
\hline & 2016 & 1.122 & 1.685 & 5.600 \\
\hline & 2017 & 1.263 & 1.702 & 5.948 \\
\hline \multirow{6}{*}{ Shell } & 2012 & 3.262 & 2.819 & 6.235 \\
\hline & 2013 & 3.199 & 2.915 & 6.164 \\
\hline & 2014 & 3.080 & 2.903 & 6.365 \\
\hline & 2015 & 2.954 & 2.805 & 6.432 \\
\hline & 2016 & 2.784 & 2.701 & 6.483 \\
\hline & 2017 & 2.761 & 2.805 & 6.432 \\
\hline \multirow{6}{*}{ TOTAL } & 2012 & 1.220 & 1.719 & 2.880 \\
\hline & 2013 & 1.167 & 1.775 & 3.521 \\
\hline & 2014 & 1.034 & 1.938 & 3.769 \\
\hline & 2015 & 1.237 & 2.023 & 3.271 \\
\hline & 2016 & 1.271 & 1.965 & 3.522 \\
\hline & 2017 & 1.346 & 1.827 & 3.990 \\
\hline \multirow{6}{*}{$\begin{array}{l}\text { Exxon } \\
\text { Mobil }\end{array}$} & 2012 & 2.185 & 5.014 & 6.174 \\
\hline & 2013 & 2.202 & 4.585 & 5.887 \\
\hline & 2014 & 2.111 & 4.476 & 5.875 \\
\hline & 2015 & 2.345 & 4.432 & 5.754 \\
\hline & 2016 & 2.365 & 4.269 & 5.482 \\
\hline & 2017 & 2.283 & 4.291 & 5.530 \\
\hline
\end{tabular}

Fonte: Relatórios Anuais das empresas Chevron,

ExxonMobil, BP, Total e Shell (vários anos). 
O primeiro elemento que deve ser destacado em relação ao Tabela 1 é o fato de que todas as companhias listadas possuem atuação a jusante e a montante da cadeia petrolífera no período recente. Também merece destaque o fato de que, para nenhuma das cinco empresas listadas, seja possível identificar um movimento de queda na produção no segmento de refino. Dito isso, depreende-se que elas não estão atualmente engajadas na implementação de uma estratégia de alienação de suas plantas de refino. Por fim, há apenas um caso (a Chevron) em que a empresa, aparentemente, retirou-se do mercado de distribuição de derivados de petróleo.

Com relação ao perfil das NOCs, Politova (2018) afirma que a cadeia de valor de uma empresa estatal do setor petrolífero tende a ser integrada, abarcando os elos de exploração, desenvolvimento, produção, transporte, processamento e distribuição de petróleo, seus derivados e gás natural. Segundo a autora, a adoção desse modelo se justifica visto que ele permite a preservação do controle sobre recursos estratégicos (POLITOVA, 2018, p. 11).

Já nos anos 1980, percebe-se iniciativas de algumas das NOCs no sentido da ocupação de elos a jusante da cadeia petrolífera. Tal processo, encabeçado pelas estatais da Venezuela ${ }^{3}$ (PDVSA), do Kuwait (Kuwait Petroleum Corporation) e da Malásia (Petronas) envolveu a aquisição de refinarias e postos de distribuição de combustíveis em outros países. Portanto, é possível perceber que nesses casos o processo de integração vertical se deu concomitantemente à internacionalização. A finalidade das aquisições internacionais de ativos localizados a jusante da cadeia petrolífera era garantir mercado para o petróleo (pesado) produzido localmente, além de tornar possível a agregação de valor ao seu produto. Essa estratégia adotada pelas NOCs que combinava integração vertical e internacionalização continuou durante os anos 1990. As estatais da Noruega, México, Emirados Árabes Unidos e Líbia adquiriram ativos no downstream, tanto na Europa, como no sudeste asiático.

Além de estarem sujeitas à regulação exercida pelo Estado, muitas NOCs atuam como reguladoras e formuladoras de políticas, em maior grau do que a maioria das outras empresas estatais. A jusante da cadeia petrolífera, as NOCs frequentemente servem

Entre 1983 e 1989, a PDVSA, por exemplo, adquiriu participações acionárias significativas em onze países europeus e comprou refinarias norte-americanas, como a CITGO, grande fabricante e distribuidora de derivados de petróleo dos Estados Unidos (Victor, Hults e Thurber, 2011). 
como reguladoras de facto do mercado doméstico de energia, supervisionando os subsídios à gasolina, os acordos de fornecimento de refinarias e outros instrumentos.

O Gráfico 1 ilustra a evolução de cinco NOCs (a saudita SaudiAramco, a iraniana NIOC, a chinesa CNPC e as russas Rosneft e Gazprom) situadas entre as principais companhias petrolíferas do mundo, nas atividades de produção de petróleo, capacidade de refino e distribuição e marketing, tomando como referência os anos de 2010 e 2017.

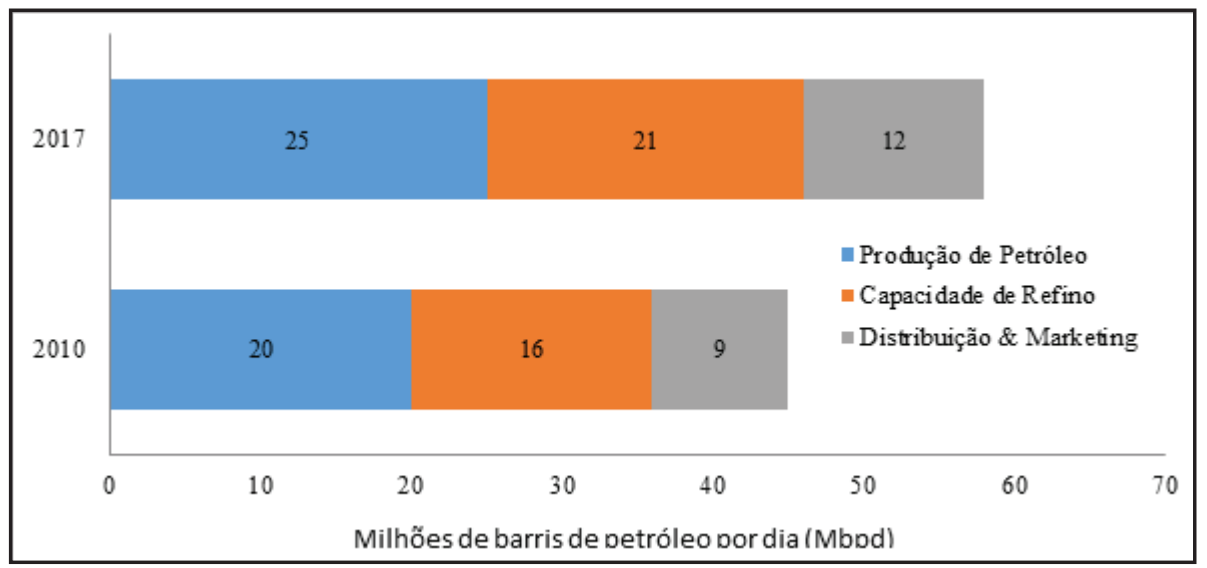

Gráfico 1 - Produção de petróleo, capacidade de refino e vendas de produtos derivados de petróleo por empresas selecionadas nos anos de 2010 e 2017 (milhões de barris/dia)

Fonte: Petroleum Intelligence (2018).

O Gráfico 1 revela que para as NOCs selecionadas a capacidade de refino cresceu tanto quando a produção de petróleo, entre 2010 e 2017. Em ambos os casos houve um incremento da ordem de $5 \mathrm{Mbpd}$. O segmento de Distribuição \& Marketing passou por uma elevação mais modesta (de $3 \mathrm{Mbpd}$ ). A principal conclusão que se pode extrair do Gráfico 1 é a de que houve uma ampliação dos empreendimentos dessas empresas, tanto a montante, como a jusante da cadeia petrolífera, o que dá sustentação a hipótese de que a integração vertical também é uma estratégia hegemônica entre as grandes empresas estatais do setor. Portanto, com base nos 
dados apresentados nesta seção, pode-se inferir que a atuação "do poço ao posto" continua a ter um papel importante do ponto de vista do modelo do modelo de organização da produção das grandes companhias de petróleo (privadas e estatais), pelas vantagens (mencionadas ao longo desta seção) que traz a tais empresas.

\section{A IMPORTÂNCIA DO REFINO NO PERFIL VERTICALMENTE INTE- GRADO DA PETROBRAS}

Com o intuito de abastecer o mercado doméstico e, desse modo, reduzir a dependência do país em relação ao petróleo importado, instituiu-se em 1953 o monopólio da União nas atividades de pesquisa, lavra, transporte e refino de petróleo e derivados exercido pela Petrobras, sociedade de economia mista criada para tal propósito. O contexto na época não era propício para que os investimentos fossem direcionados às atividades upstream, pois o preço do produto encontrava-se baixo e as pesquisas exploratórias (onshore ${ }^{4}$ ) realizadas no país não eram animadoras. Além disso, o crescimento acelerado da economia brasileira nos anos 1950 e 1960 provocou um aumento na demanda por derivados de petróleo.

Assim, até os anos 1970, a Petrobras realizou investimentos de grande monta com vistas à ampliação do parque de refino brasileiro e à constituição da infraestrutura necessária para o abastecimento interno. Nesse ínterim várias plantas de refino foram construídas e a empresa conseguiu reduzir significativamente a dependência de produtos refinados importados. Os frutos dos investimentos em refino realizados pela Petrobras foram colhidos de maneira relativamente rápida. De acordo com Macedo e Silva:

Em 1960, (...) a capacidade de refino montava a aproximadamente 190.000. Apesar disso, equivalia a $69 \%$ do consumo nacional. No ano seguinte a capacidade instalada (300.000 bpd) superou pela primeira vez o consumo. Com isso o Brasil começou a adquirira auto-suficiência na produção de derivados; em 1962, a produção nacional de óleo diesel, óleo combustível e gasolina automotiva, responsáveis, em conjunto por $85,3 \%$ do consumo de derivados, respondia por $90,0 \%$, $101,7 \%$ e $93,5 \%$ do consumo nacional (Macedo e Silva, 1985, p. 125).

\footnotetext{
Em terra
} 
É importante lembrar que nesse período o país experimentava um expressivo crescimento industrial e uma elevação em sua frota automotiva (Ponzoni, 2009). Além disso, a política de petróleo do país visava à autossuficiência na produção de combustível para superar os altos custos de importação desses produtos (Surrey, 1987).

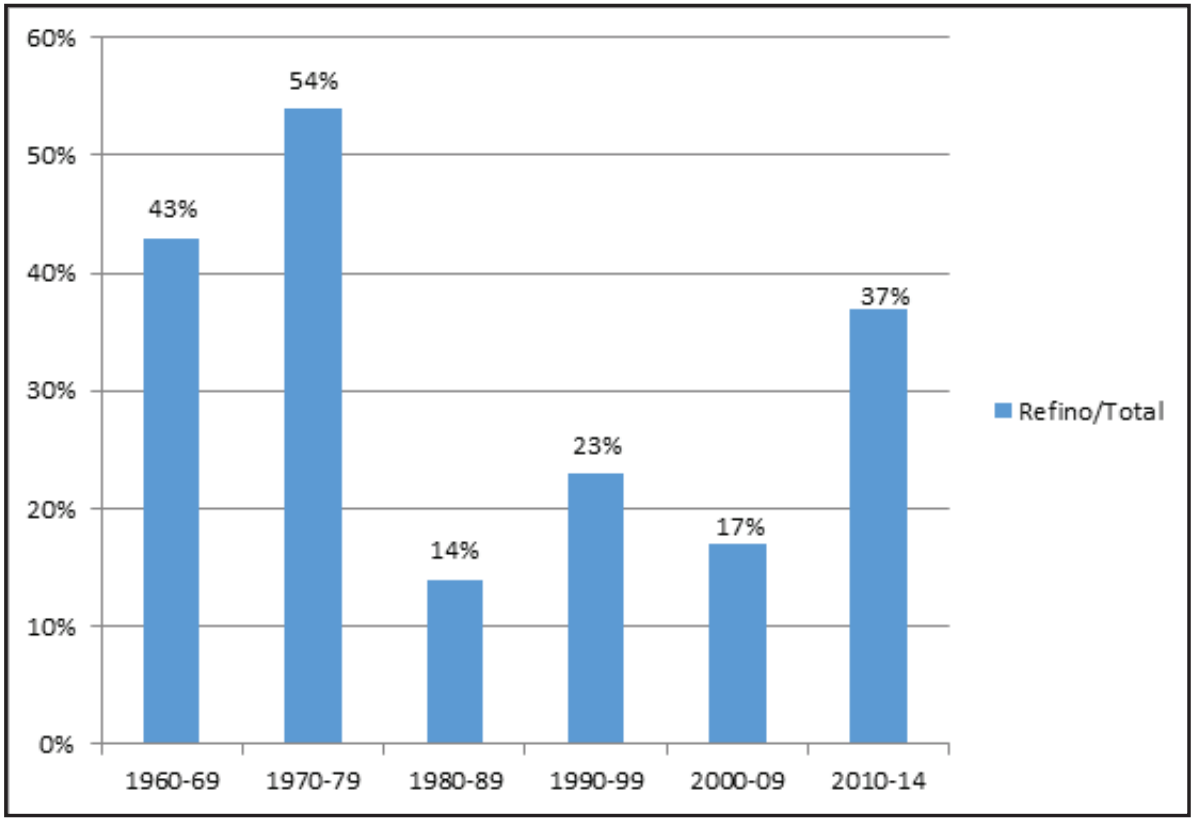

Gráfico 2 - Percentual de investimentos em downstream/investimento total da Petrobras (1960 - 2014)

Fonte: Costa (2010).

A construção de diversas plantas de petróleo permitiu que fosse alcançado um aumento expressivo da capacidade de processamento de hidrocarbonetos no Brasil. A partir dos anos 1980, o Brasil entra em um ciclo recessivo, ocasionando um arrefecimento na demanda por derivados. Nesse cenário, "a capacidade de refino tornou-se superior às necessidades do mercado nacional. Em 1984, por exemplo, havia excedentes de todos os produtos derivados de petróleo, inclusive de óleo diesel e GLP5" (Tavares, 2005, p. 138).

Além da crise dos anos 1980, o alcance da autossuficiência em derivados e os dois choques do petróleo provocaram uma ruptura

Gás Liquefeito de Petróleo 
nas estratégias da Petrobras, marcada pela substituição do downstream pelo upstream como carro chefe da carteira de investimentos da empresa. Assim, a partir dos anos 1980, observa-se uma redução da participação do setor do refino nos investimentos totais realizados pela empresa comparativamente ao período anterior (ver Gráfico 2).

As descobertas da Bacia de Campos em 1974 e do primeiro campo gigante em águas profundas (Alabacorra) em 1984 reforçaram o foco da empresa na área de Exploração e Produção. A partir de então a Petrobras ampliou largamente seus investimentos e, portanto, sua capacidade de produção de óleo bruto (ver gráfico 3). Com base nesse esforço levado a cabo pela empresa, ela conseguiu reduziu significativamente sua dependência externa, além de obter destaque internacional. O esforço tecnológico da Petrobras, caracterizado por grandes investimentos em Pesquisa e Desenvolvimento (P\&D), permitiram-na superar os desafios encontrados e a situaram na fronteira tecnológica na área de E\&P em águas profundas (Ribeiro e Furtado, 2014).

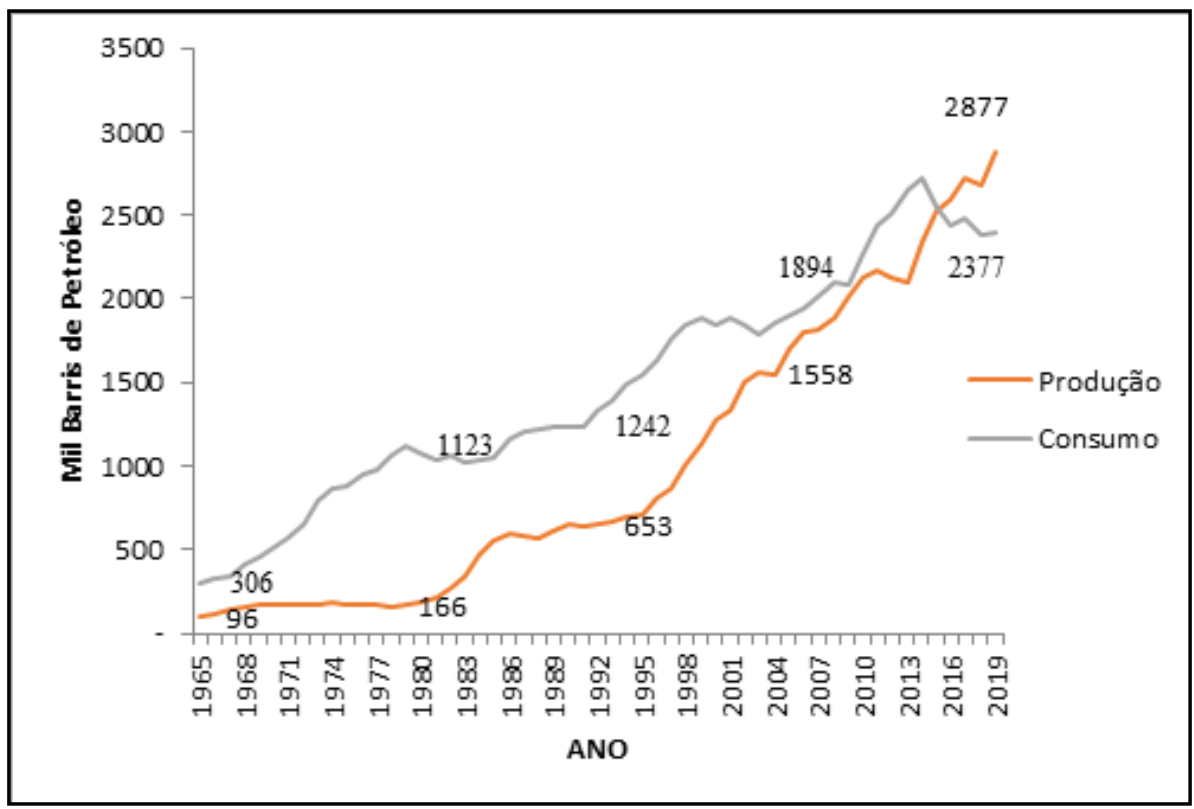

Gráfico 3 - Produção versus Consumo de Petróleo no Brasil (1965 - 2019)

Fonte: British Petroleum Statistical Review (2020). 
Mudanças importantes no setor petrolífero brasileiro ocorreram nos anos 1990, como o fim do monopólio da Petrobras em atividades a montante e a jusante da cadeia petrolífera brasileira e a criação da Agência Nacional de Petróleo ${ }^{6}$ (ANP). Todavia, mesmo após tais mudanças, tal empresa se manteve com principal player nacional nos ramos de E\&P e refino (ver Tabela 2).

Tabela 2 - Produção de Petróleo, Gás Natural e Derivados de Petróleo no Brasil: Petrobras e demais empresas no ano de 2019

\begin{tabular}{|l|l|l|}
\hline Empresa & Petróleo (barris) & $\%$ do total \\
\hline Petrobras & $754.037 .601,00$ & $74 \%$ \\
\hline Demais Empresas & $263.493 .852,00$ & $26 \%$ \\
\hline Total & 1.017 .531 .453 & $100 \%$ \\
\hline
\end{tabular}

Fonte: ANP (2020).

Em 2019, além da Petrobras, operavam no país outras 32 concessionárias na área de E\&P. Apesar disso, a Tabela 3 revela a proeminência da Petrobras, pois, apesar da quebra do monopólio do setor, naquele ano a estatal brasileira foi responsável por $3 / 4$ da produção total de óleo bruto do país. Em relação ao segmento de refino a participação da petrolífera brasileira é ainda maior. O protagonismo da Petrobras na área de refino se torna claro pela expressividade de sua participação na produção total de derivados no setor, que chega a 98\% (PETROBRAS, 2019).

Ao longo da gestão de José Sérgio Gabrielli de Azevedo ${ }^{7}$ e no início do período em que Maria das Graças Foster ${ }^{8}$ esteve na presidência da companhia é possível observar uma estratégia de fortalecimento do perfil integrado da Petrobras, com investimentos substanciais, não apenas nas atividades de E\&P, mas também em refino. Em primeiro lugar, em relação à Tabela 4, deve-se chamar a atenção para o crescimento nos investimentos totais da Petrobras durante esse período. O volume investido em 2013 é mais do que o dobro daquele observado em 2006. Quanto aos investimentos em refino, as cifras cresceram mais de cinco vezes entre 2006 e 2010 (seu pico), passando de $\mathrm{R} \$ 7,68$ bilhões para $\mathrm{R} \$ 43,75$ bilhões. Assim, a participação dos investimentos em refino no total de investimentos

\footnotetext{
Agência regulatória deste setor industrial.

Presidente da Petrobras entre 2005 e 2012.

Presidente da Petrobras entre 2012 e 2015.
} 
da empresa passou de $12 \%$ para $37 \%$ nesse período, o que corrobora que a empresa buscou reforçar seu perfil verticalmente integrado.

Tabela 3 - Petrobras: investimentos totais, investimentos em refino de petróleo e participação dos investimentos em refine sobre o total (2006 - 2013) em $R$ \$ bilhões*

\begin{tabular}{llll}
\hline ANO & $\begin{array}{l}\text { Investimentos } \\
\text { Totais }\end{array}$ & $\begin{array}{l}\text { Investimentos } \\
\text { em Refino }\end{array}$ & $\begin{array}{l}\text { Investimentos em } \\
\text { Refino/Total } \\
\text { de Investimentos }\end{array}$ \\
\hline 2006 & 61,66 & 7,68 & $12 \%$ \\
2007 & 80,36 & 18,8 & $23 \%$ \\
2008 & 90,51 & 20,38 & $23 \%$ \\
2009 & 102,91 & 26,46 & $26 \%$ \\
2010 & 117,46 & 43,75 & $37 \%$ \\
2011 & 105,29 & 39,35 & $37 \%$ \\
2012 & 114,66 & 39,33 & $34 \%$ \\
2013 & 134,1 & 39,58 & $30 \%$ \\
\hline
\end{tabular}

Fonte: Petrobras (vários anos).

*valores monetários corrigidos a partir do IPCA $(2018=100)$

** O gap entre os anos de 2003 e 2005 se deve à indisponibilidade no site da Petrobras dos relatórios anuais desses três anos.

Particularmente no que se refere à ampliação da capacidade de refino da Petrobras, tal estratégia se justificava pelo crescimento na demanda brasileira por derivados de petróleo, devido a um crescimento mais significativo da economia e ao aumento da frota de veículos do país nesse período (Mortari, 2019). Os investimentos tiveram por objetivo adaptar as unidades de refino da empresa para o processamento do óleo pesado extraído dos reservatórios brasileiros, melhorar a qualidade dos derivados produzidos nas plantas de refino da empresa, além de ampliar sua capacidade de refino.

Tais investimentos trouxeram maior flexibilidade à Petrobras, de maneira a permitir que ela definisse sua cesta de derivados de petróleo produzidos a partir do perfil de demanda e do comportamento dos preços de mercado (Petrobras, 2007 e 2008). Portanto, pode-se afirmar que a estratégia implementada pela Petrobras até recentemente no downstream esteve alinhada com os dois principais desafios da indústria global de refino, de acordo com Branco, Gomes e Szklo (2010, p. 3098): 
a primeira estratégia é aumentar a complexidade e versatilidade das refinarias; o segundo é integrar as indústrias de refino e petroquímica, agregando valor ao petróleo bruto, garantindo a participação de mercado em derivados de petróleo premium.

Com os investimentos recentes realizados pela empresa na área de refino houve um aumento de $17 \%$ na capacidade brasileira de refino entre 2007 e 2016, que passou de 2,07 Mbpd para 2,41 Mbpd (ANP, 2017).

\section{Crise na Petrobras e mudança de estratégia Para O SETOR DE REFINO}

Os prejuízos consecutivos obtidos pela empresa entre 2014 e 2017 representam manifestações de uma crise ${ }^{9}$ que, por sua vez, acabou por engendrar modificações na estratégia da empresa para o setor de refino. $\mathrm{O}$ contrachoque no preço do petróleo ${ }^{10}$, o alto grau de endividamento externo ${ }^{11}$ e os prejuízos atrelados aos casos de corrupção em que a empresa esteve envolvida podem ser citados como principais detonadores da crise. Em concordância com o que foi tratado na introdução, uma das consequências desse fenômeno foi a queda no volume de investimentos da Petrobras (ver tabela 4).

Tabela 4 - Petrobras: investimentos totais, investimentos em refino de petróleo e participação dos investimentos em refine sobre o total (2006 2014) em $R \$$ bilhões*

\begin{tabular}{llll}
\hline ANO & $\begin{array}{l}\text { Investimentos } \\
\text { Totais }\end{array}$ & $\begin{array}{l}\text { Investimentos em } \\
\text { Refino de Petróleo }\end{array}$ & $\begin{array}{l}\text { Investimentos em } \\
\text { Refino de Petróleo / } \\
\text { Investimentos Totais }\end{array}$ \\
\hline 2015 & 87,20 & 12,20 & 14 \\
2016 & 57,15 & 6,86 & 12 \\
2017 & 49,64 & 8,04 & 16 \\
2018 & 49,37 & 5,71 & 12 \\
\hline
\end{tabular}

Fonte: Petrobras (vários anos).

* valores monetários corrigidos a partir do IPCA $(2018=100)$.

\footnotetext{
9 Alguns fatores que permitem diagnosticar a crise: i) prejuízo líquido em 2014 e 2015 e no primeiro trimestre de 2016 e; ii) queda nos investimentos da empresa.

10 Tal fenômeno ocorreu entre 2014 e 2015. Para que se tenha uma ideia de sua magnitude e do poder de atingir as companhias de petróleo, houve uma oscilação no preço do barril do tipo Brent de quase US\$ 50 (de US\$ 110 para US\$ 62) entre fevereiro e dezembro de 2014 (Ribeiro, Sene e Belluzzo, 2018).

11 O endividamento líquido da empresa saltou de R\$ 103 bilhões para R \$ 392 bilhões (Petrobras, 2015).
} 
Os dados da Tabela 4 revelam o declínio dos investimentos da Petrobras em projetos na área de refino no período recente (a partir de 2016) em termos absolutos e relativos. Além do recuo dos investimentos realizados pela empresa no segmento de refino, ganhou força um novo modelo de gerenciamento de portfólio da empresa (Loural e Ferrari, 2018).

Além da queda nos investimento, a venda de ativos no segmento de refino é um dos temas que entrou na pauta do Conselho Administrativo da Petrobras. Essa ênfase na venda de ativos a jusante da cadeia fica evidente do Termo de Compromisso de Cessação (TCC) assinado com o Conselho Administrativo de Defesa Econômica (CADE), conforme trecho (apresentado abaixo) extraído do "Relatório de sustentabilidade 2019" da Petrobras:

a Petrobras assinou um Termo de Compromisso de Cessação (TCC) com o CADE, órgão que tem como missão zelar pela concorrência do mercado, se comprometendo a vender $50 \%$ do parque de refino (oito refinarias de petróleo, incluindo os ativos relacionados a transporte de combustível) (Petrobras, 2019, p. 70).

O Gráfico 4, na mesma linha, mostra como, proporcionalmente os ativos referentes ao segmento de refino perdem participação (de $26 \%$ para $20 \%$ entre 2011 e 2018 ) ao passo que a participação dos ativos ligados à E\&P parte de $44 \%$ em 2011 e chega a quase $70 \%$ em 2017 e fecha o período em $60 \%$.

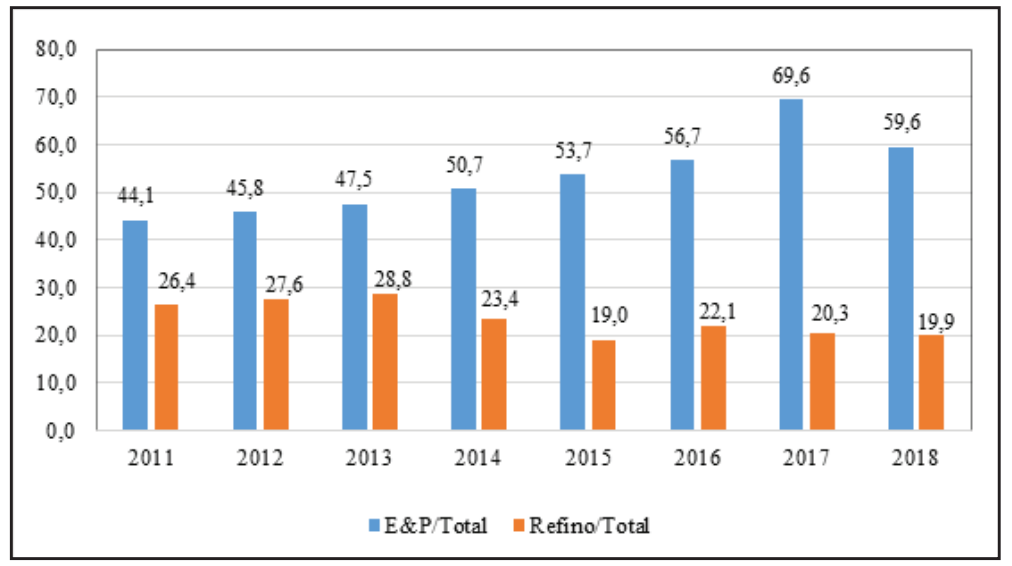

Gráfico 4 - Participação dos ativos dos segmentos de EEP e Refino no ativo total da Petrobras - em \%

Fonte: Elaboração própria a partir dos relatórios anuais da Petrobras. 
É importante ressaltar que apesar dos prejuízos apresentados pela Petrobras no segmento de refino entre 2011 e 2014, tal situação decorreu da política adotada pelo governo brasileiro à época, de controle de preços dos combustíveis. Essa política, levada a cabo pelo governo brasileiro não apenas durante esse período, mas ao longo de boa parte da trajetória da Petrobras, tem como objetivo o controle da inflação. De acordo com Almeida, Oliveira e Lozekann (2015):

A impossibilidade de repassar integralmente os preços internacionais para o consumidor implicou a renúncia de receitas pela Petrobras nos combustíveis que produz e vende no país. Adicionalmente, a empresa teve prejuízos nas importações de gasolina, diesel e GLP, vendidos abaixo do preço de compra no mercado internacional (Almeida, Oliveira e Lozekann, 2015, p. 532).

A partir da gestão de Pedro Parente, a Petrobras alterou sua política de precificação dos combustíveis que produz. O foco dessa alteração foi submeter os preços dos combustíveis vendidos no país à oscilação dos preços internacionais e da taxa de câmbio. $O$ reflexo de tal política foi a redução de uma parcela do mercado brasileiro de derivados de petróleo. Em função disso, a Petrobras passou a operar com uma ociosidade de $25 \%$ em seu parque de refino em 2018 (ver Tabela 5), ano em que ocorreu a greve dos caminhoneiros, estopim do pedido de demissão realizado por Pedro Parente do cargo de presidente da Petrobras.

Tabela 5 - Capacidade de produção e fator de utilização das plantas de refino da Petrobras (2013 - 2019)

\begin{tabular}{|l|l|l|l|l|l|l|l|}
\hline Ano & 2013 & 2014 & 2015 & 2016 & 2017 & 2018 & 2019 \\
\hline $\begin{array}{l}\text { Total (capa- } \\
\text { cidade barril/ } \\
\text { dia) }\end{array}$ & 2.203 .218 & 2.352 .192 & 2.397 .478 & 2.405 .341 & 2.405 .341 & 2.405 .341 & 2.410 .700 \\
\hline $\begin{array}{l}\text { Total (barril/ } \\
\text { dia-calendá- } \\
\text { rio) }\end{array}$ & 2.093 .058 & 2.234 .582 & 2.277 .604 & 2.285 .073 & 2.285 .073 & 2.285 .073 & 2.290 .165 \\
\hline $\begin{array}{l}\text { Fator de Utili- } \\
\text { zação (\%) }\end{array}$ & 98,2 & 94,3 & 87,1 & 80,1 & 76,2 & 75,8 & 76,5 \\
\hline
\end{tabular}

Fonte: ANP (2020). 
Deve-se enfatizar que os preços da gasolina e do diesel possuem um papel central para uma economia como a do Brasil. A greve dos caminhoneiros em 2018 e a crise de desabastecimento que tal movimento desencadeou tornaram evidentes os riscos associados à adoção de uma política que deixem os preços desses combustíveis oscilarem ao sabor do mercado. Os reflexos da política de preços adotada entre 2011 e 2014 podem ser observados no Gráfico 5. Percebe-se que no período mencionado há uma alta dos preços internacionais do barril de petróleo, ao passo que a relação entre os preços dos derivados e do barril está, em 2014, no mesmo nível de 2010, estando entre 2011 e 2013 em um patamar menor que 2010. Por outro lado, essa relação cresce de forma significativa a partir de 2015, no período em que o preço do barril sofre uma forte queda. Observa-se que, apesar da desvalorização cambial, o aumento nos preços dos derivados foi substancialmente maior.

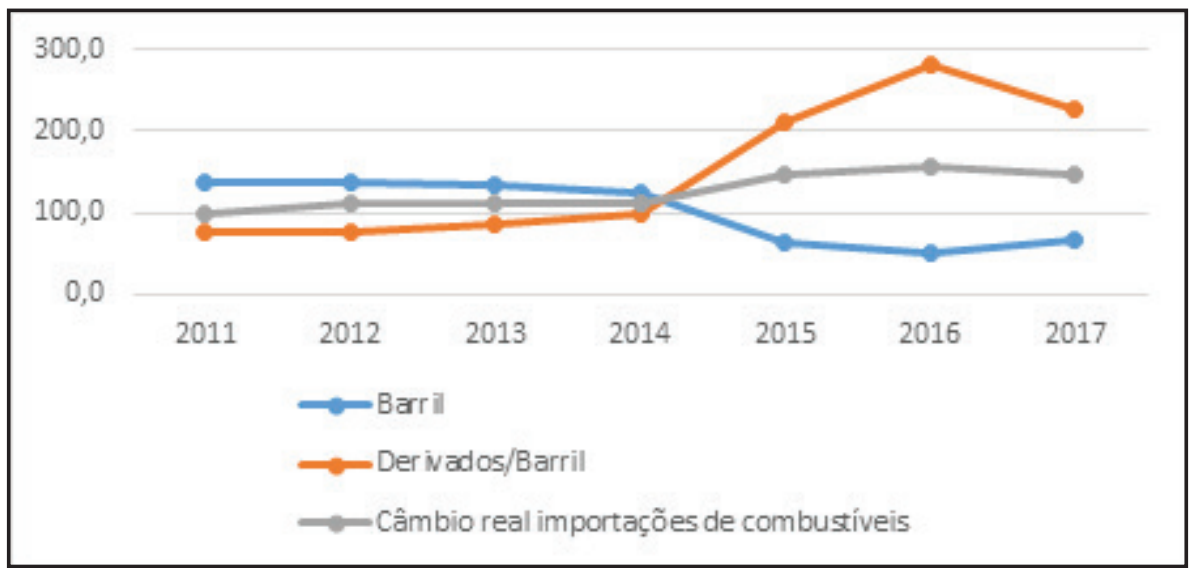

Gráfico 5 - Preços do barril de petróleo, preços relativos derivados/barril e taxa de câmbio real das importações de combustíveis - base $2010=100$.

Fontes: Elaboração própria a partir de IEA, ANP e Ipeadata. 


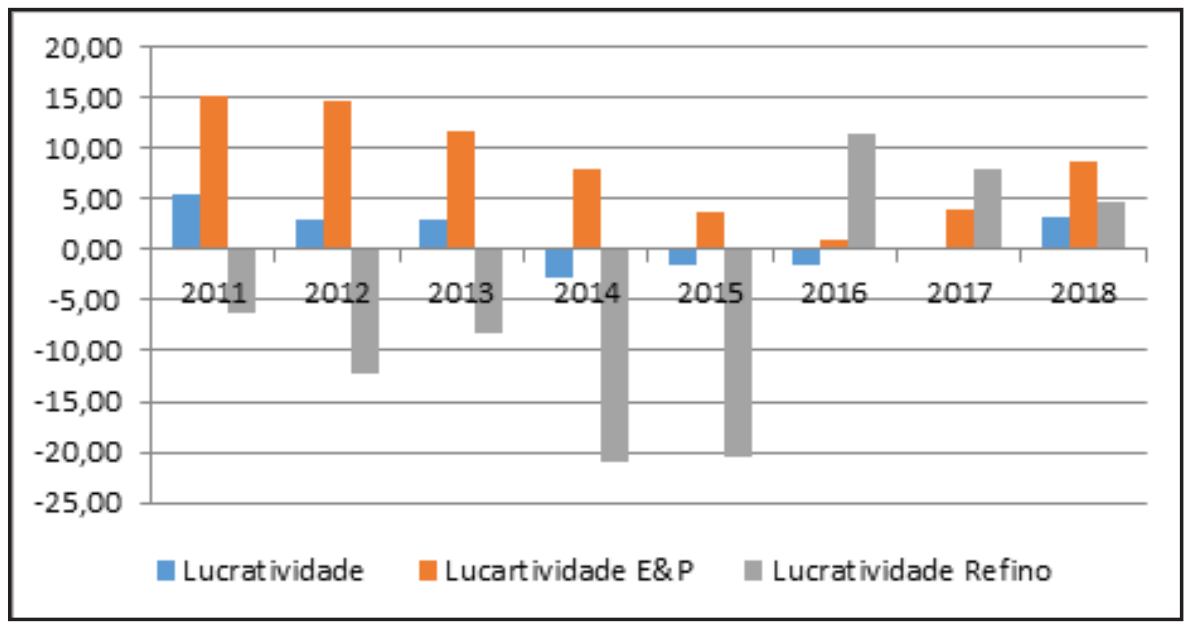

Gráfico 6 - Lucratividade da Petrobras (lucro líquido/ativo total)

- Total, Exploração e Produção e Refino - em \%

Fonte: Elaboração própria a partir dos relatórios anuais da Petrobras.

O Gráfico 6 mostra a lucratividade da Petrobras como um todo e o mesmo indicador nos segmentos de E\&P e Refino. A atividade de refino apresenta prejuízo de 2011 a 2015, sendo um resultado bastante negativo nos dois últimos anos do período. Até 2014 o resultado se explica, em parte, pela política de preços adotada e em 2015, também parcialmente, pela desvalorização cambial que afetou o preço das importações de derivados. Entre 2016 e 2018, contudo, a atividade de refino se mostra lucrativa à empresa. Percebe-se que de 2013 a 2016 há um movimento de queda da lucratividade do segmento de E\&P, seguindo a baixa dos preços internacionais do barril de petróleo. Com a lucratividade da atividade de E\&P muito baixa em 2016 e ainda pequena em 2017, é o segmento de refino que assegura um menor prejuízo no primeiro caso e um lucro zero no segundo.

Conforme destacado na seção 2 deste artigo, o refino ocupa uma posição importante nas estratégias das grandes companhias de petróleo (privadas e estatais), visto que trata-se de uma atividade que mitiga os riscos atrelados ao câmbio, bem como no preço do óleo cru. Nesse sentido, o refino contrabalança prejuízos que eventualmente ocorram na área de Exploração e Produção, em períodos nos quais o preço do barril de petróleo está baixo. Ademais a ati- 
vidade de refino contribui para a geração de fluxo de caixa futuro, sobretudo em cenários de câmbio desvalorizado. Assim, no limite, a venda de ativos no segmento de refino pode prejudicar a geração de fluxo de caixa e, consequentemente o ritmo de descoberta de novas jazidas, minando a competitividade da empresa no longo prazo. Concluindo, há que se questionar se a estratégia de alienação de ativos é de fato a mais apropriada à Petrobras.

\section{Considerações Finais}

As descobertas no pré-sal descortinaram grandes oportunidades, no médio e longo prazo, para que o país se torne não apenas exportador de óleo bruto, mas também de derivados de petróleo, especialmente porque o óleo produzido nos reservatórios do pré-sal possui qualidade superior àquele encontrado na bacia de Campos. No entanto, em função da crise recente enfrentada pela Petrobras e da mudança nos rumos da empresa a partir as segunda metade da década de 2010, emerge com força uma estratégia de alienação de seus ativos no segmento de refino.

Conforme ressaltado neste artigo, esse movimento se situa na contramão da estratégia de verticalização amplamente empregada pelas grandes companhias de petróleo (privadas e estatais). A atividade de refino ocupa uma posição importante no modelo de negócios dessas empresas, pois, apesar de muitas vezes apresentarem oportunidades de lucros mais reduzidos do que aqueles alcançados nas atividades de E\&P, o refino mitiga os riscos atrelados a alterações no câmbio e no preço do petróleo. Além disso, em períodos de baixa no preço do barril de petróleo, o segmento de refino contrabalança as perdas que frequentemente ocorrem nessas situações às companhias de petróleo, atrelados às atividades na área de E\&P.

Outro a ser considerado é o fato de que a desintegração vertical pode minar a competitividade de uma empresa petrolífera. Conforme destacado na seção 2, como estamos diante de um setor intensivo em capital, apenas as companhias de petróleo que atuam do "poço ao posto" terão condições de recursos para produzir um fluxo de renda que seja abundante e estável, tornando possível a realização de investimento a montante da cadeia, isto é, na prospecção de novas reservas, dentro de um timing necessário. 
É importante ressaltar que apesar dos prejuízos apresentados pela Petrobras no segmento de refino entre 2011 e 2014, tal situação decorreu da política adotada pelo governo brasileiro à época, de controle de preços dos combustíveis. Trata-se de uma política, empregada com frequência por diferentes governos no decorrer de boa parte da trajetória da estatal brasileira, cujo alvo principal o controle da inflação. Assim, além de ser ver obrigada a renunciar de parte da receita que poderia ser obtida nos combustíveis que produz e vende, a empresa também se depara com prejuízos nas importações derivados como gasolina e diesel, vendidos no marcado brasileiro abaixo dos custos de aquisição no mercado internacional.

Por fim, além dos fatores ligados aos resultados financeiros da Petrobras, não se deve deixar de levar em conta a importância do setor de refino para o desenvolvimento industrial, devido ao seu potencial de encadeamento. A relevância do setor reforça o papel estratégico exercido pela Petrobras no desenvolvimento industrial brasileiro no período recente.

\section{REFERÊNCIAS}

AGÊNCIA NACIONAL DO PETRÓLEO (ANP). Anuário estatístico (vários anos). Disponível em: https://dados.gov.br/organization/88609f8c-a0ee-46eb-9294-f2175a6b561e?res_format=CSV\&page=3. Acesso em: 25 mar. 2021.

ALMEIDA, E. L. F.; OLIVEIRA, P. V.; LOSEKANN, L. Impactos da contenção dos preços de combustíveis no Brasil e opções de mecanismos de precificação. Brazilian Journal of Political Economy, v. 35, n. 3, p. 531 - 556, 2015.

BARBOZA, A. C. Análise de investimentos em refino na Petrobras em ambiente concorrencial, 1996, 129 f. (Tese de Doutorado COPPE), Universidade Federal do Rio de Janeiro, Rio de Janeiro.

PEROBELLI, Fernando S.; HADDAD, Eduardo A.; POSSAS, Glaucia; FARINAZZO, Rodrigo A. Interdependência e encadeamento das exportações setoriais e os modais de transporte: um enfoque insumo produto. Revista econômica do Nordeste, v. 41, n. 3, p. 455-474, 2010.

CASTELO BRANCO, David A.; GOMES, Gabriel L.; SZKLO, Alexandre S. Challenges and technological opportunities for the oil refining industry: A Brazilian refinery case. Energy Policy, n. 38, p. 3098-3105, 2010.

BRITISH PETROLEUM (BP). Our business model. Disponível em: <https://www.bp.com/en/ global/corporate/what-we-do/our-business-model.html> Acesso em: maio 2018.

BRITISH PETROLEUM (BP). Annual Report (vários anos). Disponível em: https://www.bp.com/ en/global/corporate/investors/results-and-reporting/annual-report/annual-reporting-archive. html\#tab_2. Acesso em: jun. 2018. 
BRITISH PETROLEUM (BP). Statistical Review of World Energy. Disponível em: http:// www.bp.com/en/global/corporate/energy-economics/statistical-review-of-world-energy.html. Acesso em: 02 set. 2018.

BRITISH PETROLEUM (BP). Downstream investor day 2017. Disponível em: https://www. bp.com/en/global/corporate/investors/investor-presentations/presentation-archive.html\#tab_11. Acesso em: 01 set. 2020.

CARLTON, D.; PERLOFF, J. Modern Industrial Organization. Boston: Pearson/Addison-Wesley, 2005.

CHEVRON. Annual Report. Disponível em: https://www.chevron.com/-/media/chevron/ annual-report/2017/2017-Annual-Report.pdf. Acesso em: jul. 2018.

COASE, R. H. The nature of the firm. Economica, v. 4, n. 16, p. 386-405, 1937.

CORREIO BRASILIENSE. Petrobrás deve lançar em três meses pacote para venda de refinarias. Correio Brasiliense, 01 de mar. 2019. Disponível em: https:/www.correiobraziliense.com.br/ app/noticia/economia/2019/03/01/internas_economia,740571/petrobras-deve-lancar-em-tres-meses-pacote-para-venda-de-refinarias.shtml. Acesso em: 26 mar. 2019.

COSTA, P. R. (2010). Petrobras - Abastecimento Business Plan 2010-2014: Agregando Valor Através do Ciclo do Negócio de Downstream. November 2010. Disponível em: https:// $w w w \cdot g o o g l e \cdot c o m \cdot b r / u r l$ ? sa=t\&rct=j\&q=\&esrc=s\&source=web\&cd=1\&ved=0ahUKEwic1IzMg_PXAhWEIpAKHeyKC50QFggoMAA\&url=http\%3A\%2F\%2Fwww.investidorpetrobras.com. br\%2Fdownload\%2F1381\&usg=AOvVaw2TGW8JorIM-oWATn8BKmIO. Acesso em: 15 jan. 2018.

COUTINHO, F. Refino e Política de Preços da Petrobrás, alerta aos presidenciáveis. Associação dos Engenheiros da Petrobrás, 2018. Disponível em: https://www.aepet.org.br/w3/index.php/ conteudo-geral/item/2070-refino-e-politica-de-precos-da-petrobras-alerta-aos-presidenciaveis. Acesso em: 02 set. 2020.

EXXONMOBIL. Annual Report. Disponível em: https://cdn.exxonmobil.com/ /media/global/ files/summary-annual-report/2017-summary-annual-report.pdf. Acesso em: 28 jun. 2018.

FEHLAUER, D. K.; VIEIRA, A. M.; CLARO, J. A. C. S. Pesquisa em administração e sua relação com o plano nacional de pós-graduação. Gestão e Desenvolvimento, v. 16, n. 3, p. 83-105, 2019.

FURTADO, A. T.; MULLER, N. Competitividade da indústria brasileira de petróleo. Revista Brasileira de Energia, v. 4, n. 1, p. 93-114, 1995.

INSTITUTO BRASILEIRO DE GEOGRAFIA E ESTATÍSTICA (IBGE). Pesquisa Industrial Anual: Empresa. Disponível em: <https://www.ibge.gov.br/estatisticas-novoportal/economicas/industria/9042-pesquisa-industrial-anual.html?=\&t=o-que-e> Acesso em: 23 fev. 2018.

LOURAL, M. S.; FERRARI, V. E. O conflito entre acionistas e gestores e o caso da Petrobrás. In: III Encontro Nacional de Economia Industrial e Inovação, 2018, Uberlândia. Anais eletrônicos... Uberlândia: UFU, 2018. Disponível em O conflito entre acionistas e gestores e o caso da Petrobrás. Acesso em: 21 jan. 1997.

LUCCHESI, C. F.. Petróleo. Estudos avançados, v. 12, n. 33, p. 17-40, 1998. 
MACEDO e SILVA, A. C. Petrobras: a consolidação do monopólio estatal e a empresa privada (1953-1964). 1985. Dissertação (Mestrado em Economia) - Instituto de Economia, Universidade Estadual de Campinas, Campinas.

MORTARI, V. S. Evidências empíricas da importância da indústria brasileira de refino de petróleo. Uberlândia, 2019. 119f. Dissertação (Mestrado). Instituto de Economia e Relações Internacionais, Universidade Federal de Uberlândia.

PERISSÉ, J. B. Evolução do Refino de Petróleo no Brasil. Rio de Janeiro, 2007. 1658f. Dissertação (mestrado). Programa de Pós-Graduação em Engenharia Química, Universidade do Estado do Rio de Janeiro.

PETROBRAS. Relatório de Administração 2006. 2009. 2010. 2014. 2016. 2017. 2018. Disponível em: http://www.investidorpetrobras.com.br/pt/relatorios-anuais/relatorio-de-administracao. Acesso em: 22 fev. 2019.

PETROBRAS. Relatório de sustentabilidade 2019. Disponível em: https://sustentabilidade. petrobras.com.br/src/assets/pdf/Relatorio-Sustentabilidade.pdf. Acesso em: 01 set. 2020.

PETROLEUM INTELLIGENCE WEEKLY. Energy Intelligence Top 100: Global NOC \& IOC Rankings. Petroleum Intelligence Weekly, 2018.

PINELLI, Marcelo Santos.; PERTUSIER, Rafael Resende. Perspectivas de investimento para o refino mundial. In: Anais do $3^{\circ}$ Congresso Brasileiro de P\&D em Petróleo e Gás, 2005, Salvador. Anais eletrônicos... Natal-RN, Associação Brasileira de Petróleo e Gás Natural. Disponivel em: http://www.portalabpg.org.br/PDPetro/3/trabalhos/IBP0277_05.pdf. Acesso em: 22 mar. 2021.

POLITOVA, Marina. M\&A as strategic response to oil price shock. St. Petersburg, 2018. 64f. Dissertação (Mestrado). Graduate School of Management, St. Petersburg State University.

PONZONI, L. K. Capacitação tecnológica e inovação na indústria de refino de petróleo no Brasil: o caso Petrobrás. Rio de Janeiro, 2009. Dissertação (Mestrado). Instituto de Economia, Universidade Federal do Rio de Janeiro.

RIBEIRO, Cássio G; FURTADO, André T. Government Procurement Policy in Developing Countries: The Case of Petrobras. Science Technology and Society, v. 19, p. 161-197, 2014.

RIBEIRO, Cássio G.; SENE, Túlio S.; ALBA NETO, Henrique B. A oscilação do preço do petróleo: uma análise sobre o período entre 2010-5. Estudos Internacionais, v. 6, n. 1, p. 87-106, 2018.

RUAS, J. A. G. Dinâmica de concorrência na indústria parapetrolífera offshore: evolução mundial do setor de equipamentos subsea e o caso brasileiro. Campinas, 2012. 329f. Tese de Doutorado. Universidade Estadual de Campinas, 2012.

SHELL. Annual Report (vários anos). Disponível em: https://www.shell.com/investors/financial-reporting/annual-publications/annual-reports-download-centre.html. Acesso em: jun. 2018.

SURREY, John. Petroleum development in Brazil: the strategic role of a national oil company. Energy Policy, v. 15, n. 1, p. 7-21, 1987.

TAVARES, Marina Elisabete Espinho. Análise do refino no Brasil: estado e perspectivas-uma análise "cross-section". Rio de Janeiro, 2005. 402f. Tese (doutorado). Programa de em Engenharia, Universidade Federal do Rio de Janeiro. 
TEBBOUNE, Sofiane; URQUHART, Cathy. Netsourcing strategies for vendors: Aresource-based and transaction cost economics perspective. Journal of Information Technology, v. 3, n. 1, 32-47, 2016.

TOTAL. Annual report and publications (vários anos). Disponível em: https://www.total.com/ en/investors/publications-and-regulated-information/reports-and-publications\#annualReports. Acesso em: jun. 2018.

VALENTE, F.S.P.F. A dinâmica da acumulação de capital e os movimentos de fusões e aquisições em estruturas de mercado oligopolísticas: um estudo focado na evolução recente da indústria mundial do petróleo. Dissertação de Mestrado. Universidade Estadual de Campinas, 2009.

WILLIAMSON, O. E. Markets and hierarchies: Analysisand antitrust implications. New York: Free Press, 1975.

WILLIAMSON, O. E. The economic institutions of capitalism: Firms, markets, relational contracting. New York: Free Press, 1985.

ZYLBERSZTAJN, D. Estruturas de governança e coordenação do agribusiness: uma aplicação da nova economia das instituições. São Paulo, 1995. 241f. Tese (Livre Docência em Administração) - Faculdade de Economia, Administração e Contabilidade, Universidade de São Paulo.

ZYLBERSZTAJN, D. Papel dos contratos na coordenação agro-industrial: Um olhar além dos mercados. In J. P. de Souza \& I. N. Prado (Orgs.), Cadeias produtivas: Estudos sobre competitividade e coordenação. Maringá: EDUEM, 2009, pp. 38-74.

Recebido em: 25-3-2021

Aprovado em: 3-12-2021

Avaliado pelo sistema double blind review.

Disponível em http://mjs.metodista.br/index.php/roc 